\title{
MODEL PENGARUH DIAMETER PIPA TERHADAP PRESSURE DROP PADA PIPA PLTP DOMINASI UAP
}

\author{
CUKUP MULYANA* DAN NAUFAL RIYANDI \\ Departemen Fisika Fakultas MIPA Universitas Padjadjaran, \\ Jl. Raya Bandung-Sumedang Km 21,Jatinangor 45363 \\ *email : c.mulyana55@yahoo.com
}

\begin{abstract}
Abstrak. Pada Pembangkit Listrik Tenaga Panas Bumi (PLTP), fluida panas bumi yang mengalir dari suatu komponen ke komponen lainnya akan mengalami perubahanperubahan besaran. Satu di antaranya adalah penurunan tekanan atau pressure drop. Pressure drop adalah istilah yang digunakan untuk menggambarkan penurunan tekanan dari satu titik dalam pipa atau tabung kehilir titik yang disebabkan oleh factor gesekan pada pipa, diameter pipa, fitting, dan bilangan Reynold. Pressure drop penting diketahui dan biasanya digunakan dalam perancangan awal PLTP agar tekanan yang akan masuk ketiap-tiap komponen PLTP sesuai dengan tekanan yang telah di set. Model penelitian ini dilakukan untuk mengetahui pengaruh dari diameter pipa terhadap nilai penurunan tekanan dengan anggapan tidak ada kehilangan panas dan condensate traps, serta variasi kekasaran pipa. Model penelitian ini menghasilkan nilai penurunan tekanan berbanding terbalik dengan besarnya diameter pipa. Ketika diameter pipadiperbesar dari ukuran $0.254 \mathrm{~m}-1.397 \mathrm{~m}$, nilai penurunan tekanan pada kekasaran 0.00003 , semakin mengecil dari 89.173 bar - 2.844 bar sedangkan nilai penurunan tekanan pada kekasaran 0.00009 semakin mengecil dari 107.799 bar - 2.845 bar.
\end{abstract}

Kata kunci : PLTP, Pressure Drop, Diameter Pipa, Kekasaran Pipa, Fitting.

Abstract. In Geothermal Power Plants (PLTP), geothermal fluid flowing from one component to another will cause changes in magnitude. One of them is pressure drop. Pressure drop is a term used to describe the pressure drop from one point in a pipe or tube downstream from a point caused by friction factors in the pipe, pipe diameter, fittings, and Reynold number. Pressure drop is important to know and is usually used in the initial design of geothermal power plants so that the pressure that will enter each component of the geothermal power plant according to the pressure set. This research model was conducted to determine the effect of pipe diameter on the value of pressure reduction with the assumption that there was no heat loss and condensate traps, and there were variations in pipe roughness. This research model produces a pressure drop value inversely proportional to the diameter of the pipe. When the pipe diameter is enlarged from the size of $0.254 \mathrm{~m}-1,397 \mathrm{~m}$, the value of the pressure drop at 0.00003 decreases from 89,173 bar - 2,844 bar while the value of pressure drop at roughness is 0.00009 decreasing from 107,799 bar - 2,845 bar.

Keywords: PLTP, Pressure Drop, Pipe Diameter, Pipe Roughness, Fitting.

\section{Pendahuluan}

PLTP adalah pembangkit listrik yang memanfaatkan panas bumi sebagai sumber energinya [1]. Beberapa komponen dalam PLTP adalah sumur produksi geothermal, separator, dan turbin yang mana tiap komponen tersebut akan dihubungkan dengan pipa. Fluida panas bumi bergerak dari sumur produksi 
menuju separator untuk dipisahkan menjadi uap kering. Fluida berupa uap kering dari separator akan bergerak kembali menuju turbin dan dikonversi menjadi listrik.

Fluida yang mengalir dari sumur hingga ke turbin tersebut tentunya akan mengalami perubahan-perubahan besaran yang sangat penting, satu di antaranya adalah terjadi penurunan tekanan (pressure drop). Pressure drop adalah istilah yang digunakan untuk menggambarkan penurunan tekanan dari satu titik dalam pipa atau tabung ke hilir titik [2].

Nilai penurunan tekanan penting diketahui untuk digunakan dalam perancangan PLTP. Hal ini dimaksudkan agar tekanan yang akan masuk ke tiap-tiap komponen PLTP sesuai dengan tekanan yang telah di set pada komponen-komponen tersebut. Jika tekanan yang keluar pada segmen pipa lebih kecil daripada tekanan yang telah di set maka daya yang dihasilkan tidak optimal. Jika tekanan yang masuk pada komponen PLTP lebih besar dari tekanan yang telah di set maka akan menyebabkan kerusakan komponen dan menimbulkan kerugian dalam bidang ekonomi untuk biaya perbaikan atau pergantian [3]. Faktor-faktor yang mempengaruhi besarnya penurunan tekanan adalah diameter pipa, panjang pipa, faktor gesekan pada pipa, bilangan Reynold, kecepatan alir fluida, dan fitting pada pipa $[4,5]$. Model dari penelitian ini dilakukan untuk mengetahui pengaruh dari diameter pipa terhadap besarnya nilai pressure drop pada pipa dengan kemiringan 50 yang menghubungkan separator dan turbin dengan sambungan berupa bends 900 sebanyak tiga unit.

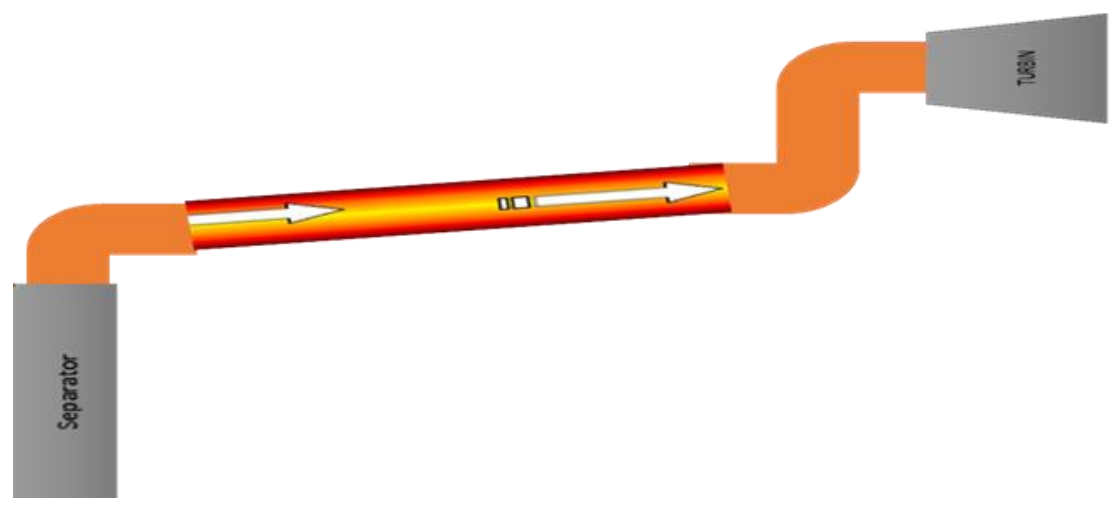

Gambar 1. Objek Penelitian

Model dari penelitian ini diharapkan dapat memberikan manfaat dalam mengetahui pengaruh dari diameter pipa terhadap besarnya nilai pressure drop, memperkirakan berapa tekanan yang akan masuk ke turbin, memperkirakan daya yang akan dihasilkan oleh turbin, mengetahui maintenance yang tepat dalam peningkatan performa pembangkit akibat adanya pressure drop.

\section{Metode Penelitian}

Pada model penelitian ini, yang pertama dilakukan adalah pengamatan lapangan dan pengambilan data lapangan. Pada tahap ini, data yang didapat berupa panjang pipa, diameter pipa, kekasaran pipa, tekanan masuk pipa, volume spesifik, viskositas, dan laju alir massa. Setelah itu dilakukan pengolahan data untuk mendapatkan nilai pressure drop dengan persamaan-persamaan berikut. 


$$
\begin{gathered}
V_{s}=\frac{\dot{m} v_{s}}{\pi(d / 4)} \\
R e=\frac{V_{s} d}{v_{s} \mu_{g}} \\
\lambda=8\left[(8 / R e)^{12}+\frac{1}{(A+B)^{3 / 2}}\right]^{1 / 12}
\end{gathered}
$$

Dengan nilai A dan B:

$$
\begin{gathered}
A=\left[2.457 \ln \frac{1}{(7 / R e)^{0.9}+0.27 \varepsilon / d}\right]^{16} \\
B=\left[\frac{37530}{R e}\right]^{16}
\end{gathered}
$$

Dengan kehilangan tekanan akibat fitting berupa belokan (bend):

$$
\Delta P_{\text {fitting }}=\left(\sum K_{r} \frac{V_{s}^{2}}{2 g}\right) p s i \times 0.0689476 \text { bar }
$$

Sehingga pressure drop:

$$
\Delta P=\lambda \frac{l V_{s}^{2}}{d\left(2 v_{s} \times 10^{5}\right)}+\left(\frac{1}{v_{s}} g \sin \theta\right)+\Delta P_{\text {fitting }}
$$

Tekanan masuk turbin $=P$ masuk pipa $-\Delta P$

$V_{s}=$ kecepatan alir fluida $(\mathrm{m} / \mathrm{s}), \dot{m}=$ laju alir massa $(\mathrm{kg} / \mathrm{s}), v_{s}=$ volume spesifik $\left(\mathrm{m}^{3} / \mathrm{kg}\right), \mathrm{d}=$ diameter pipa $(\mathrm{m}), \mathrm{Re}=$ bilangan Reynold, $\mu_{g}=$ viskositas fluida $(\mathrm{kg} / \mathrm{m} \mathrm{s}), \lambda=$ friction factor, $\mathrm{g}=$ percepatan gravitasi $\left(\mathrm{m} / \mathrm{s}^{2}\right), \theta=$ kemiringan pipa $\left({ }^{\circ}\right), \Delta P=$ pressure drop (bar), $K_{r}=$ resistance coefficient

\section{Hasil dan Pembahasan}

Untuk menghitung parameter pipa pada kekasaran tertentu diperlukan data pengamatan lapangan seperti yang dicantumkan pada tabel 1 .

Tabel 1. Hasil Pengamatan Lapangan

\begin{tabular}{cccccc}
\hline $\begin{array}{c}\text { Panjang Pipa } \\
(\mathrm{m})\end{array}$ & $\begin{array}{c}\text { Kekasaran } \\
\text { Pipa }\end{array}$ & $\begin{array}{c}\text { Laju Alir } \\
\text { Massa }(\mathrm{kg} / \mathrm{s})\end{array}$ & $\begin{array}{c}\text { Volume } \\
\text { Spesifik }\left(\mathrm{m}^{3} / \mathrm{kg}\right)\end{array}$ & $\begin{array}{c}\text { Tekanan } \\
\text { Masuk Pipa } \\
(\text { bar })\end{array}$ & $\begin{array}{c}\text { Koefisien } \\
\text { Resisten } \\
\text { Bending }\left(90^{\circ}\right)\end{array}$ \\
\hline \multirow{2}{*}{1000} & $\begin{array}{c}0.00003 ; \\
0.00009\end{array}$ & 48.3 & 0.3427 & 5.5 & 0.9 \\
\hline
\end{tabular}

Data pada tabel 1 diolah menggunakan pesamaan 1 sampai 8 dengan diameter pipa yang bervariasi. Beberapa hasil pengolahan datanya tertera pada tabel 2 berikut. 
Tabel 2. Hasil Pengolahan Data pada Kekasaran Pipa 0.00003

\begin{tabular}{|c|c|c|c|c|c|c|c|c|c|c|}
\hline $\begin{array}{l}\text { Diamet } \\
\text { er pipa } \\
\text { (m) }\end{array}$ & $\begin{array}{c}\text { Kecepat } \\
\text { an alir } \\
\text { uap } \\
(\mathrm{m} / \mathrm{s})\end{array}$ & $\begin{array}{l}\text { Bilang } \\
\text { an } \\
\text { Reynol } \\
\text { d }\end{array}$ & $\begin{array}{c}\text { Faktor } \\
\text { friksi }\end{array}$ & $\begin{array}{c}\text { Pressu } \\
\text { re drop } \\
\text { friction } \\
\text { (bar) }\end{array}$ & $\begin{array}{c}\text { Pressure } \\
\text { drop } \\
\text { kemiring } \\
\text { an (bar) }\end{array}$ & $\begin{array}{c}\text { Pressu } \\
\text { re drop } \\
\text { fitting } \\
1 \text { (bar) }\end{array}$ & $\begin{array}{c}\text { Pressu } \\
\text { re drop } \\
\text { fitting } \\
2 \text { (bar) }\end{array}$ & $\begin{array}{c}\text { Pressu } \\
\text { re drop } \\
\text { fitting } \\
3 \text { (bar) }\end{array}$ & $\begin{array}{c}\text { Pressu } \\
\text { re drop } \\
\text { total } \\
\text { (bar) }\end{array}$ & $\begin{array}{c}\text { Tekananmas } \\
\text { uk turbin } \\
\text { (bar) }\end{array}$ \\
\hline 0.254 & 326.535 & $\begin{array}{c}1.73 \mathrm{x} \\
10^{7}\end{array}$ & $\begin{array}{c}0.012 \\
49\end{array}$ & 76.514 & 2.495 & 3.388 & 3.388 & 3.388 & 89.173 & 0 \\
\hline$\ldots$ & $\cdots$ & $\cdots$ & $\cdots$ & $\cdots$ & $\cdots$ & $\cdots$ & $\cdots$ & $\cdots$ & $\cdots$ & $\cdots$ \\
\hline 1.397 & 10.795 & $\begin{array}{c}3.14 \mathrm{x} \\
10^{6}\end{array}$ & $\begin{array}{c}0.010 \\
61\end{array}$ & $\begin{array}{c}0.0129 \\
1\end{array}$ & 2.495 & 0.112 & 0.112 & 0.112 & 2.844 & 2.656 \\
\hline
\end{tabular}

Tabel 3.HasilPengolahan Data padaKekasaranPipa 0.00009

\begin{tabular}{|c|c|c|c|c|c|c|c|c|c|c|}
\hline $\begin{array}{c}\text { Diamet } \\
\text { er pipa } \\
(\mathrm{m})\end{array}$ & $\begin{array}{c}\text { Kecepatanv } \\
\text { alir uap } \\
(\mathrm{m} / \mathrm{s})\end{array}$ & $\begin{array}{l}\text { Bilang } \\
\text { an } \\
\text { Reynol } \\
\text { d }\end{array}$ & $\begin{array}{l}\text { Fakto } \\
\text { r } \\
\text { friksi }\end{array}$ & $\begin{array}{c}\text { Pressu } \\
\text { re } \\
\text { drop } \\
\text { frictio } \\
n \text { (bar) }\end{array}$ & $\begin{array}{c}\text { Pressure } \\
\text { drop } \\
\text { kemiring } \\
\text { an (bar) }\end{array}$ & $\begin{array}{c}\text { Pressu } \\
\text { re } \\
\text { drop } \\
\text { fitting } \\
1 \text { (bar) }\end{array}$ & $\begin{array}{c}\text { Pressu } \\
\text { re } \\
\text { drop } \\
\text { fitting } \\
2 \text { (bar) }\end{array}$ & $\begin{array}{c}\text { Pressu } \\
\text { re } \\
\text { drop } \\
\text { fitting } \\
3 \text { (bar) }\end{array}$ & $\begin{array}{c}\text { Pressu } \\
\text { re } \\
\text { drop } \\
\text { total } \\
\text { (bar) }\end{array}$ & $\begin{array}{c}\text { Tekananma } \\
\text { suk turbin } \\
\text { (bar) }\end{array}$ \\
\hline 0.254 & 326.535 & $\begin{array}{c}1.73 \mathrm{x} \\
10^{7}\end{array}$ & $\begin{array}{c}0.015 \\
53\end{array}$ & 95.139 & 2.495 & 3.388 & 3.388 & 3.388 & $\begin{array}{c}107.79 \\
9\end{array}$ & 0 \\
\hline$\ldots$ & $\ldots$ & $\ldots$ & $\ldots$ & $\ldots$ & $\ldots$ & $\ldots$ & $\cdots$ & $\ldots$ & $\ldots$ & $\ldots$ \\
\hline 1.397 & 10.795 & $\begin{array}{c}3.14 \mathrm{x} \\
10^{6}\end{array}$ & $\begin{array}{c}0.011 \\
85\end{array}$ & $\begin{array}{c}0.0144 \\
2\end{array}$ & 2.495 & 0.112 & 0.112 & 0.112 & 2.845 & 2.656 \\
\hline
\end{tabular}

Dari tabel 2, perubahan diameter pipa akan berpengaruh pada besarnya nilai penurunan tekanan. Pada kekasaran pipa 0.00003, ketika diameter pipa sebesar $0.254 \mathrm{~m}$, nilai penurunan tekanannya sebesar 89.173 bar. Ketika diameter pipa diperbesar menjadi $1.397 \mathrm{~m}$, nilai penurunan tekanannya menurun menjadi 2.844 bar. Hal ini dikarenakan ketika diameter pipa diperbesar dari ukuran $0.254 \mathrm{~m}$ sampai $1.397 \mathrm{~m}$, menyebabkan luas permukaan pipa semakin besar. Besarnya luas permukaan pipa akan berpengaruh terhadap besarnya laju aliran uap yang mengalir pada pipa PLTP. Sesuai dengan persamaan kontinuitas yaitu ketika luas permukaan semakin besar, laju aliran uap akan semakin kecil yaitu dari 326.535 $\mathrm{m} / \mathrm{s}$ sampai dengan $10.795 \mathrm{~m} / \mathrm{s}$. Laju aliran uap ini akan berpengaruh kepada jenis aliran uap yang terukur dari bilangan Reynoldnya. Bilangan Reynold semakin mengecil seiring dengan diperbesarnya diameter pipa, yaitu dari 1.73 x 107 sampai 3.14 x 106 yang artinya turbulensi dari aliran tersebut semakin berkurang. Berkurangnya sifat turbulensi akan menyebabkan gesekan-gesekan antara uap panas bumi dengan permukaan pipa semakin berkurang juga. Oleh karena itu, 
seiring dengan berkurangnya gesekan tersebut, menyebabkan besarnya penurunan tekanan (pressure drop) juga semakin kecil.

Besarnya penurunan tekanan juga dipengaruhi oleh kemiringan pipa dengan sudut kemiringan 50 dan adanya tiga unit fittings berupa belokan atau bends dengan sudut 900. Nilai penurunan tekanan akibat kemiringan adalah 2.495 bar. Besar atau kecilnya nilai penurunan tekanan akibat kemiringan ini dipengaruhi oleh percepatan gravitasi dan sudut kemiringan dari pemasangan pipa. Semakin besar sudut kemiringannya, penurunan tekanan akan semakin besar. Pada penurunan tekanan akibat fittings, dalam kasus ini berupa tiga unit belokan ukuran 900, nilainya semakin mengecil seiring dengan membesarnya diameter pipa. Yaitu dari 3.388 bar sampai 0.112 bar. Nilai tekanan ini sama untuk tiap-tiap belokan. Selain karena diameter, besar kecilnya penurunan tekanan akibat belokan ini juga disebabkan oleh koefisien belokannya, dalam hal ini, untuk 900 akan bernilai 0.9. Nilai pressure drop yang semakin kecil akan membuat tekanan yang akan masuk ke turbin semakin besar sehingga dapat diketahui hubungan antara diameter pipa dan tekanan yang akan masuk turbin berbanding lurus. Ketika diameter pipa diperbesar dari ukuran $0.254 \mathrm{~m}$ sampai $1.397 \mathrm{~m}$, tekanan yang akan masuk turbin juga akan meningkat dari 0 bar hingga 2.656 bar. Pada diameter pipa $0.254 \mathrm{~m}$ sampai dengan $0.501 \mathrm{~m}$, tekanan dianggap 0 karena besarnya penurunan tekanan jauh lebih besar daripada tekanan yang masuk ke pipa, dalam penelitian ini 5.5 bar, sehinga tidak mungkin tekanan bernilai negatif. Hal ini juga dapat diartikan tidak ada daya yang dihasilkan turbin.

Pada penelitian ini dilakukan variasi kekasaran pipa, yaitu dengan kekasaran 0.00009 yang tertera pada tabel 3. Ketika menggunakan kekasaran pipa tersebut, nilai penurunan tekanan bernilai lebih besar daripada nilai dengan kekasaran pipa 0.00003. Ketika diameter pipa sebesar $0.254 \mathrm{~m}$, penurunan tekanan yang dihasilkan bernilai 107.799 bar dan ketika diameter pipa diperbesar menjadi 1.397 $\mathrm{m}$, penurunan tekanannya menjadi 2.845 bar. Hal ini menunjukan bahwa semakin kasar permukaan pipa akan menyebabkan nilai pressure drop semakin besar.

Untuk melihat perbandingan antara kedua variasi kekasaran pipa tersebut dapat dilihat pada gambar 2 dan 3 .

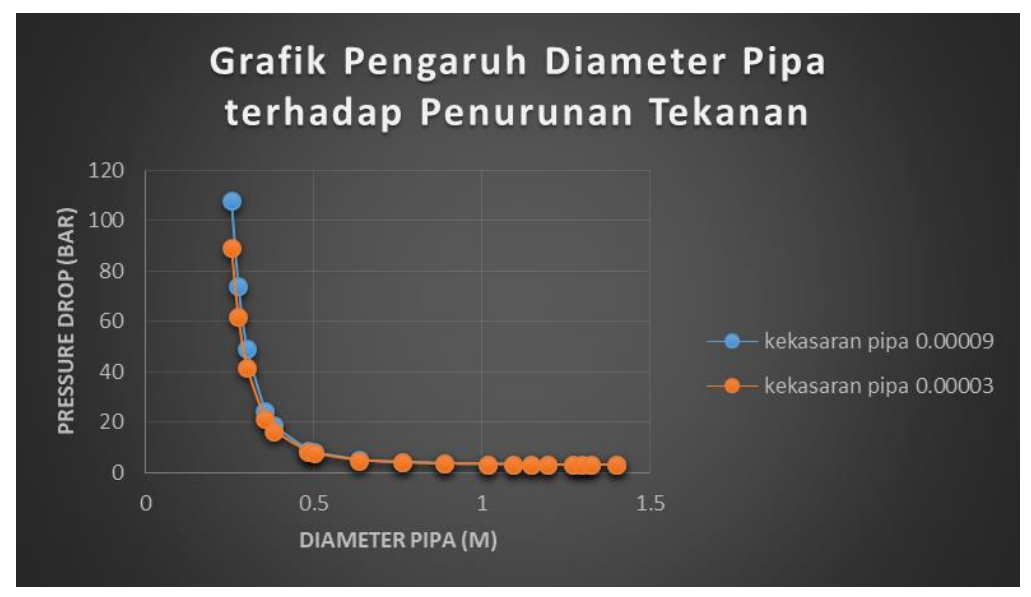

Gambar 2. Grafik hubungan diameter pipa terhadap penurunan tekanan 


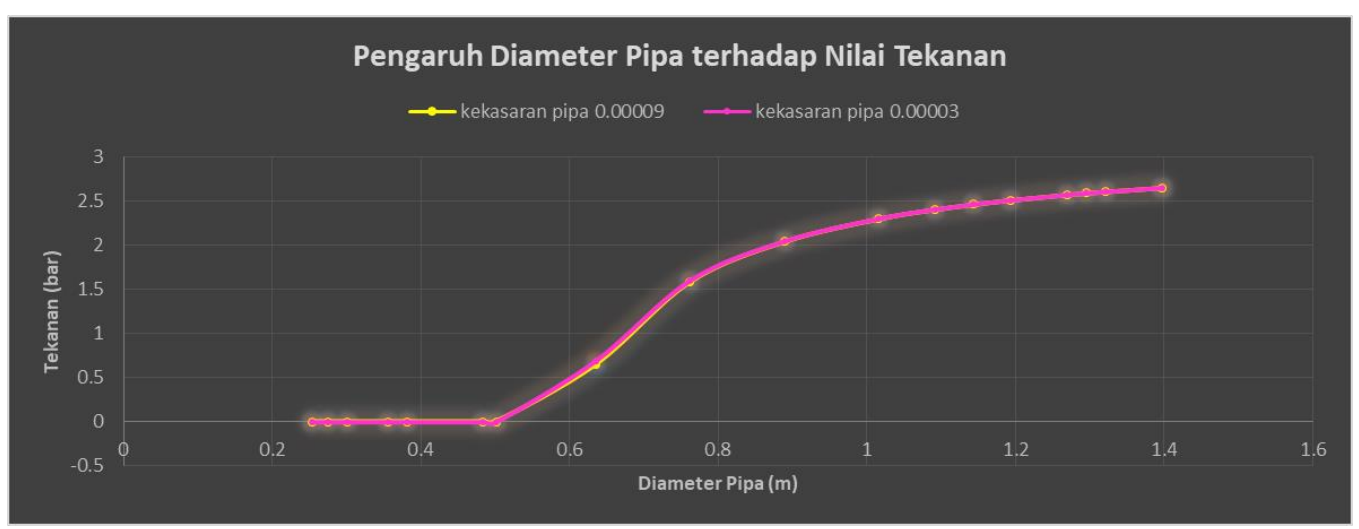

Gambar 3. Grafik hubungan diameter pipa terhadap tekanan masuk turbin

Pada gambar 2, terlihat kekasaran pipa 0.00003 yang berwarna jingga memiliki nilai penurunan tekanan yang lebih kecil daripada kekasaran pipa 0.00009 yang berwarna biru. Sehingga terlihat pada gambar 3, tekanan yang akan masuk ke turbin dengan kekasaran 0.00003 yang berwarna merah muda akan bernilai lebih besar daripada kekasaran 0.00009 yang berwarna kuning.

Pada diameter $0.254 \mathrm{~m}$ sampai $0.889 \mathrm{~m}$, terjadi perubahan pressure drop yang signifikan, namun setelah itu, yaitu dari $1.016 \mathrm{~m}$ sampai $1.397 \mathrm{~m}$, perubahan pressure drop tidak terlalu besar atau cenderung konstan. Hal ini dapat diartikan bahwa pada batasan diameter tertentu, perubahan penurunan tekanan dalam pipa tidak akan terlalu signifikan. Pada batasan itu pula, perbedaan baik nilai penurunan tekanan maupun tekanan yang akan masuk urbin antara dua variasi tersebut tidak jauh berbeda.

Hal ini dapat dimanfaatkan dalam pemilihan pipa yang akan digunakan. Semakin halus permukaan pipa maka harga pipa akan semakin mahal. Semakin besar diameter pipa, harga pipa tersebut akan semakin mahal. Karena pada batasan tertentu perubahan diameter dan variasi kekasaran pipa tidak berpengaruh terlalu besar terhadap penurunan tekanan, maka dapat dipilih pipa yang memiliki diameter paling kecil dalam rentang tersebut dan juga pipa yang permukaannya tidak terlalu halus. Sehingga PLTP dapat bekerja dengan optimal namun tidak memakan biaya terlalu besar.

\section{Kesimpulan}

Hubungan antara diameter pipa dan penurunan tekanan adalah berbanding terbalik. Semakin besar diameter pipa, semakin kecil penurunan tekanannya. Pada model penelitian ini, ukuran diameter divariasikan dari $0.254 \mathrm{~m}$ sampai $1.397 \mathrm{~m}$ dengan dua variasi kekasaran yaitu 0.00003 dan 0.00009 . Hasilnya, pada kekasaran pipa 0.00003 pressure drop-nya memiliki nilai dari 89.173 bar sampai 2.844 bar. Pada kekasaran pipa 0.00009 pressure drop-nya memiliki nilai dari 107.799 bar sampai 2.845 bar Pada batasan-batasan diameter pipa tertentu, nilai penurunan tekanan perlahan akan menjadi konstan dan perubahan diameter tidak memberikan perubahan tekanan yang signifikan. 


\section{DaftarPustaka}

1. L. J. Dwiatmanto, Pembangkit Listrik Tenaga Panas Bumi (PLTP) dan Kendala Pembangunannya. Orbith, Vol. 11 No. 1 (2015) p. 60-67.

2. E. Yohana, A. I. Saputra, Analisa Pressure Drop dalamInstalasi Pipa PT.Pertamina Drilling Services Indonesia dengan Pendekatan Bingham Plastic. ROTASI, Jurnal Teknik Mesin, Vol. 17 No. 4 (2015) p. 170-174.

3. Horasdo. 2008. Pengaruh Penurunan Tekananpada Sistem Pemipaan Terhadap Performansi Optimum dari Sumur Produksi. Depok: Universitas Indonesia.

4. N. M. Saptadji, Teknik Panas Bumi. Bandung: Penerbit ITB, 2009.

5. B. J. Suroto, Pengaruh Nilai Wettability pada Pool Boiling Heat Transfer Studi Kasus Hydrophobic, Hydrophilic dan Superhydrophilic, Jurnal Ilmu dan Inovasi Fisika Vol 01. No. 01 (2017) p. 65-69. 